\title{
Cotidiano de trabalhadores urbanos na Parahyba moderna
}

\author{
Waldeci Ferreira Chagas
}

\section{SciELO Books / SciELO Livros / SciELO Libros}

CHAGAS, WF. Cotidiano de trabalhadores urbanos na Parahyba moderna. In: OLIVEIRA, TB., org. Trabalho e trabalhadores no Nordeste: análises e perspectivas de pesquisas históricas em Alagoas, Pernambuco e Paraíba [online]. Campina Grande: EDUEPB, 2015, pp. 141-158. ISBN 978-85-7879-

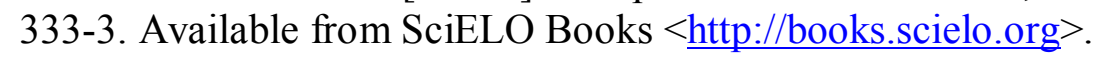

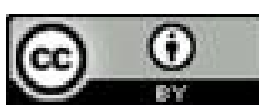

All the contents of this work, except where otherwise noted, is licensed under a Creative Commons Attribution 4.0 International license.

Todo o conteúdo deste trabalho, exceto quando houver ressalva, é publicado sob a licença Creative Commons Atribição 4.0.

Todo el contenido de esta obra, excepto donde se indique lo contrario, está bajo licencia de la licencia Creative Commons $\underline{\text { Reconocimento 4.0. }}$ 


\section{Cotidiano de trabalhadores \\ urbanos na Parahyba moderna}

Waldeci Ferreira Chagas

O processo de modernização por que passaram as cidades brasileiras, nas três primeiras décadas do Século XX, apesar da perspectiva de torná-las espaços aprazíveis e saudáveis aos olhos das elites urbanas, também incidiu sobre a vida das classes pobres, sobretudo, dos trabalhadores urbanos.

Neste artigo, caminhamos pela cidade da Parahyba, atual Joáo Pessoa, do início do Século XX, e nos atemos a apontar as transformaçóes no cotidiano de alguns trabalhadores, visto que o projeto de modernizaçáo e urbanizaçáo dessa cidade transformou não só o cotidiano dos moradores da área central, mas também dos trabalhadores, sobretudo, porque algumas categorias passaram a morar nas ruas próximas à área central, em decorrência das atividades que executavam e devido ao fato de os locais de trabalhos ficarem no centro dessa cidade. Porém, suas casas foram consideradas pelos médicos e engenheiros como insalubres, portanto, indesejáveis para a convivência com a urbe moderna.

No percurso que fazemos pelas ruas, deparamo-nos com alguns trabalhadores que foram afastados para os arredores da cidade sob o argumento de que suas casas não correspondiam aos padróes estabelecidos pelos órgáos governamentais ou porque suas práticas culturais eram consideradas incompatíveis com o que se esperava fosse digno de uma pessoa moderna. Assim, os 
trabalhadores, com suas casas e seus hábitos cotidianos, foram apontados como indesejáveis e, portanto, teriam que se afastar para dar lugar aos serviços e aos equipamentos urbanos implantados em uma Parahyba modernizada.

Os serviços de infraestrutura urbana executados na cidade da Parahyba, durante as três primeiras décadas do Século XX, embora relevantes, não foram suficientes para manter a nova cidade. Não bastou aformosear a Parahyba, construir novas residências, abrir e alargar ruas, construir praças e jardins. $\mathrm{O}$ estado sanitário dessa cidade ainda era precário e sempre pairava o risco de epidemias se alastrarem, tais como gripe, febre amarela, tuberculose, varíola e pneumonia, principalmente porque fazia parte das preocupaçóes o grande contingente de gente pobre que habitava nos arredores próximos ao centro e que, todos os dias, deslocava-se de suas casas para trabalhar nas lojas, nas oficinas, nas fábricas ou nas feiras livres.

Diante dessa realidade, os médicos encaravam os trabalhadores urbanos como transmissores das patologias, razáo por que passaram a alertar os prefeitos e os governadores sobre a necessidade de se aplicarem as medidas profiláticas cabíveis para combater as doenças de modo a garantir a salubridade e consolidar a Parahyba, de fato, como uma cidade moderna. Assim, para os médicos, a modernidade também significou preocupação com as classes pobres, principalmente com os trabalhadores, considerados como os indivíduos excluídos dos benefícios da modernização e da urbanização, mas que compartilhavam experiências e culturas semelhantes nesse processo, ainda que náo ocupassem posiçóes idênticas nas relaçóes sociais e de produçáo. Estamos nos referindo aos operários, aos estivadores, aos arrumadeiros e aos cabeceiros.

A perspectiva dos médicos era a de que algumas medidas de disciplinarização deveriam ser aplicadas para contê-los e evitar que permanecessem na cidade e enfeiassem-na. Apesar de os trabalhadores estarem envolvidos no processo de produçáo de mercadorias, poucos se beneficiaram da modernizaçáo da cidade.

A disciplinarização sobre o uso do espaço urbano foi um 
mecanismo de distribuição dos indivíduos em espaços individualizados, capazes de assegurar que a cidade continuasse civilizada. Esse tipo de procedimento fora decorrente da imagem formulada pelas elites acerca das classes pobres, principalmente dos trabalhadores, vistos como ignorantes, rudes e incivilizados. Portanto, eram homens e mulheres, cujos comportamentos foram considerados incompatíveis com a modernidade, e cuja expressão deveria ser contida para que não contrariassem a ordem estabelecida.

A preocupação dos médicos não atingia as condiçôes em que os trabalhadores viviam, mas recaia, sobretudo, no perigo que eles representavam. Temia-se não só a prática de roubos e saques, mas também a possibilidade de transmitir patologias. Dessa forma, o próprio corpo dos pobres acabou sendo alvo de temor e de repúdio. Como veremos, a necessidade de retê-los e de controlar a eles próprios e aos seus costumes foi uma das principais preocupaçôes das elites e resultou na elaboraçáo de várias leis e códigos e na fundação de instituiçóes de caridade e auxílio que tinham os objetivos de vigiar, afastar e domar os trabalhadores.

Assim, a modernizaçáo da Parahyba, apesar de ter se constituído como um processo limitado, sagrou-se eficiente na elaboraçáo de medidas de controle social e, ao longo das três primeiras décadas do Século XX, o governo estadual e o municipal utilizaram medidas autoritárias para manter a disciplina no uso do espaço público urbano a fim de assegurar a higienizaçáo da cidade. Contudo, a desobediência às determinaçôes do governo republicano foi uma constante, visto que até os trabalhadores assalariados não tinham condiçôes de adquirir, construir ou pagar aluguel de uma casa e continuaram residindo nos casebres. Essa foi uma forma de contrariar o governo e de não se adequar à proposta imposta.

Os trabalhadores foram, então, lembrados pelos médicos como classes danosas à sociedade e, portanto, deveriam ser recolhidas às instituições de caridade. Ao invés de lhes assegurar condiçóes para que se mantivessem dignamente, os médicos pregavam a manutenção da modernidade. Nesse sentido, a modernidade também significou a aplicação de algumas medidas profiláticas fundamentadas na ciência e cujo objetivo era o de manter 
a cidade ideal. De modo geral, as açóes implementadas de caráter assistencialista/paternalista construíram a imagem dos trabalhadores como classe perigosa e legitimaram seu afastamento para os arredores da cidade.

Para assegurar a modernidade entre os paraibanos, o Código de Postura foi aplicado e tanto os engenheiros quanto os médicos e os delegados de polícia fiscalizaram sua efetivação. As posturas incidiam sobre uma série de questôes pertinentes à habitação urbana. As casas deveriam ser de tijolo e cobertas de telhas, com janelas frontais e laterais indispensáveis à circulaçáo do ar e à entrada dos raios solares. Segundo os médicos sanitaristas, essas condiçóes deixavam o ambiente sempre arejado e livre da contaminação de qualquer patologia contraída pelo ar. As residências ainda deveriam ser alinhadas uma às outras, em relaçáo ao limite da rua, e o proprietário obrigado a fazer a manutenção das condiçôes básicas de higiene, como pintar a fachada externa pelo menos duas vezes no ano, manter a frente e as laterais sempre limpas e não jogar lixo na rua, mas armazená-lo em depósito adequado para ser recolhido posteriormente. Por isso, muitos moradores tiveram que abandonar suas casas, que logo foram demolidas pelas autoridades, por náo estarem compatíveis com o Código de Postura. Enquanto o Código de Postura foi aplicado, acentuouse a divisáo entre pobres e ricos, e a área central da cidade foi se constituindo, por excelência, no espaço das elites.

A partir de 1920, foram proibidas a construçáo de casas de palha no perímetro urbano e a permanência de casebres e cortiços considerados moradias insalubres e de estrutura arquitetônica destoante das recomendaçóes indicadas. Essas medidas tinham o propósito de assegurar o aspecto saudável e aprazível da cidade e de afastar as classes pobres da área central, porque as condiçóes de insalubridade de suas moradias foram consideradas um perigo para a saúde. O Código de Postura, pelo menos no que diz respeito às normas de habitação, assegurou às classes dominantes a condiçáo de pertencimento à urbe, instituiu aos trabalhadores o estranhamento a ela, pois náo os considerou moradores da cidade, mas um problema a ser afastado. É importante ressaltar que 
o Estado e a Prefeitura não tinham açóes que visassem construir casas para os trabalhadores em condiçôes higiênicas e salubres em outros lugares da cidade.

Para combater o perigo representado pela moradia dos trabalhadores, as ações da Repartição de Higiene foram reforçadas de forma que o dirigente desse órgáo se tornou a principal figura no cumprimento do referido código que, por sua vez, legitimava as práticas médicas sanitárias. Paralelamente a isso, os médicos ainda uniram seu saber ao poder político dos prefeitos, o que levou esses profissionais a orientarem e a instrumentalizarem, via Prefeitura, propostas que visavam melhorar o estado sanitário da cidade. Essa união resultou na implementaçáo efetiva do Código de Postura e contribuiu para que a Prefeitura e a Repartição de Higiene fiscalizassem a aplicação das determinaçôes relativas ao ordenamento do espaço urbano. Devido a isso, a construçáo das casas passou a depender náo só das orientaçóes médicas, mas também, sobretudo, da autorização do prefeito. O objetivo dessa medida era de coibir a desorganizaçáo que outrora caracterizara o cenário urbano e, principalmente, mantê-lo salubre e higienizado.

Assim como em outras cidades brasileiras, como o Rio de Janeiro, São Paulo e Recife, por exemplo, na Parahyba, os médicos sanitaristas agiram como engenheiros sociais, empenhados em criar espaços higiênicos contra as doenças e contágios, especialmente as patologias associadas às condiçóes de vida em que as classes pobres viviam. Como exemplo do ocorrido em São Paulo e no Rio de Janeiro, na Parahyba, a Associação Médica, fundada em 1927, também se constituiu como um espaço de discussão acerca do estado sanitário da cidade e de elaboração de recomendaçôes pertinentes à modernização. Nas discussóes fomentadas pelos médicos, as condiçóes sanitárias passaram a ser ponto de pauta principal, pois, segundo eles, eram capazes de combater várias doenças. Por isso, exigiam a atenção do prefeito e do governador, principalmente porque os trabalhadores habitavam e trafegavam no cenário urbano, o que, para os médicos, era um problema manter a salubridade e a modernizaçáo. Sob o ponto de vista dos médicos sanitaristas, as condiçóes das casas, a falta 
de luz elétrica e de acesso à água encanada e tratada, além do estado de subnutriçáo dos trabalhadores tornavam-nos vulneráveis à aquisiçáo de doenças, em especial, as relacionadas ao aparelho respiratório, como gripe, pneumonia e tuberculose ${ }^{1}$.

De início, os médicos sugeriram aos prefeitos várias medidas, dentre elas, a demolição dos casebres, a implementaçáo da campanha de vacinação contra a varíola, a limpeza das vias públicas, a reorganização do serviço de saúde e a criação da comissão de vacinação. Essas medidas passavam pelo cumprimento do Código de Postura. Foram propostos, ainda, a ampliaçáo do esgoto sanitário e o calçamento das ruas localizadas fora do perímetro central da cidade. Esses profissionais temiam que as doenças se propagassem em meio às condiçóes de insalubridade de algumas artérias da cidade habitadas pelos trabalhadores.

Enquanto os médicos exigiram dos prefeitos açôes pertinentes à manutençáo de um estado sanitário saudável na cidade, os moradores da área central passaram a denunciar à Repartição de Higiene as famílias pobres que ainda insistiam em morar em casas consideradas insalubres naquele perímetro. Esse tipo de procedimento decorreu, em parte, do fato de os médicos sanitaristas que estavam à frente desse órgáo de saúde recomendarem a demoliçáo dos casebres onde porventura residisse ou tenha residido um doente acometido por varíola. Náo demorou, e essa patologia passou a ser denominada de "doença de pobre" e por isso, os casebres, os mocambos e os cortiços passaram a ser vistos como detentores das condições necessárias à reprodução do vírus dessa patologia. Náo se denunciavam apenas as condiçóes da casa, mas também os moradores, pois, na perspectiva da manutenção da cidade saudável e salubre, eles passaram a ser vistos como agentes transmissores. O fotógrafo Manuel Gonçalves da Silva, popularmente conhecido como "Voltaire Dalva", residente à Rua Barão do Triunfo, fora vítima desse processo. $\mathrm{O}$ autor da denúncia contra esse trabalhador e artista ressaltou que a casa onde tal sujeito insistia em morar,

1 Ver atas das reuniōes da Associação Médica da Parahyba de 1923, 1924, 1925, 1926, 1927 , 1928, 1929 e 1930. 
há vários meses, havia sido condenada pela Repartição de Higiene Pública, e o proprietário convidado a fechá-la e abandoná-la por ter sido considerada incompatível com os novos preceitos de higiene, visto que tal residência colaborava com a insalubridade da cidade, no entanto, mantinha-se habitada ${ }^{2}$.

Esse tipo de denúncia é elucidativo de como os moradores da área central da cidade incorporaram o significado da cidade moderna. $\mathrm{Na}$ insistência de que as autoridades administrativas tomassem providências cabíveis quanto às casas insalubres, o denunciante lembrava que, devido às más condiçôes do domicílio, não se tratava de uma casa, mas de um "pardieiro imoral, um barrento buraco de porta e janela. Internamente possui uns letreiros que mais parece que funcionava uma bodega, ou coisa parecida" ${ }^{3}$.

Conforme tais palavras do denunciante, a casa onde o fotógrafo habitava "não apresentava condiçóes de abrigar um ser humano". Embora o denunciante náo quisesse entender, a permanência do Senhor Manuel Gonçalves da Silva numa casa insalubre se devia à sua pouca condição econômica, uma vez que era comum o trabalhador não ter onde morar nem condiçóes de arcar com as despesas do aluguel de uma casa de portas e janela, nos moldes definidos pelos médicos sanitaristas.

Apesar de o denunciado ser um fotógrafo, portanto, um profissional pouco comum na década de 1920, sobretudo entre as classes pobres, sua presença na área da cidade habitada pelos estivadores e carregadores se devia ao fato de seu estúdio de fotografia ter sido incendiado, o que o deixou impossibilitado de reconstruí-lo e de continuar exercendo sua profissão. Por essa razão, teve que continuar morando nos escombros que restaram da casa. A condição de sua casa e o estado de abandono em que vivia transformaramno em uma pessoa indesejável aos olhos da elite à qual pertencia o autor da denúncia, que, embora se referisse ao fotógrafo com

2 Com a higiene. A União, Parahyba, 25 jan. 1920, p. 1.

3 Ibidem. 
cordialidade, chamando-o de "Voltaire Dalva", queria vê-lo distante do espaço da cidade aprazível, desconsiderando a condição social desfrutada pelo fotógrafo outrora e o episódio de que fora vítima. $\mathrm{Na}$ compreensão do denunciante, o fotógrafo desconhecia os hábitos de higiene e, por essa razão, morava numa casa insalubre.

Esse caso, embora se refira a um trabalhador que, por causa de um incêndio, perdeu as condições sociais de que desfrutava, é ilustrativo da intolerância das elites com as classes trabalhadoras, em geral, as classes pobres. Supostamente Manuel Gonçalves da Silva, ou "Voltaire Dalva", já frequentara os espaços das elites, sobretudo, em momentos de trabalho, mas no momento em que se encontrava habitando uma casa insalubre, todos o queriam distante da área central.

$\mathrm{Na}$ dúvida sobre quem havia concedido autorização para o fotógrafo continuar morando na casa onde fora encontrado, mesmo ela tendo sido considerada insalubre e alvo de denúncia no jornal, disse o denunciante:

Náo sabemos realmente quem autorizou a reabertura daquele ninho de percevejos. Queremos crer, porém, que o atual inquilino ali penetrou furtivamente, instalou-se e contrapôs-se as determinaçôes da Repartição de Higiene, contrariando não só esse órgão de saúde púbica, como também a beleza arquitetônica da urbe, pois que aquele buraco não poderia ser novamente habitado. Por isso, apelamos mais uma vez para o Dr. Vital de Mello, para que ele tome as providências cabíveis, porque sem dúvida as suas determinaçóes tem sido e estáo sendo burladas. Acredito que o nobre médico providenciará sem demora a solução, fazendo evacuar o pardieiro da Rua Barão do Triunfo, uma vez que é uma ofensa à estética daquela rua e uma infração aos princípios da salubridade pública ${ }^{4}$. 
A salubridade e a estética urbana eram faces da mesma moeda e não combinavam com as condiçóes e os estilos de vida dos trabalhadores, sobretudo, de suas moradias, pois, apesar de ser uma casa insalubre, reconhecida pelos médicos como um risco à saúde, a questão que motivou a denúncia não foi somente essa, mas também o fato de sua estrutura destoar da estética arquitetônica da cidade. De certa forma, os adjetivos pejorativos atribuídos ao imóvel se deveram às condiçóes estruturais em que se encontrava, o que o tornava incompatível com as residências da área onde estava localizado. Os escombros quebravam a perspectiva do embelezamento e do aformoseamento desejados para as ruas da cidade da Parahyba, característicos das ruas das urbes modernas. Esse tipo de compreensão e a atitude da denúncia resultaram da influência das imagens arquitetônicas das cidades do Rio de Janeiro, de Recife e de São Paulo sobre os paraibanos e passaram a justificar as medidas tomadas, uma vez que a perspectiva era a de assemelhar a Parahyba a essas cidades.

Além de instituir uma política de demoliçóes, a ordem dos médicos era de mandar queimar os restos dos casebres e barracos, para impedir que as pessoas reaproveitassem os materiais para a construção de um barraco em outro local da cidade. A queima dos restos de materiais, segundo os médicos, evitaria que a cidade continuasse correndo o risco de contaminaçáo, razão pela qual foi utilizada a força policial. Frente a essa determinação, os trabalhadores e suas famílias passaram a ser deslocados para algumas artérias da cidade, como a Rua Formosa, a Rua da Raposa e a Rua do Melão5.

Outra vítima da racionalização do espaço urbano e obrigada a se afastar para os espaços periféricos na cidade da Parahyba foi o operário Ernesto Teixeira, cuja casa foi demolida e os restos de materiais incendiados. Havia dias que ele recebera da Repartição de Higiene as recomendaçóes de que abandonasse a casa onde morava por ter sido considerada insalubre ou que construísse no local uma de tijolo e coberta de telha ${ }^{6}$. Por não dispor de

5 A Uniáo, Parahyba, $1^{\circ}$ mar. 1913, p. 3.

6 Relatório da Chefatura de Polícia encaminhado ao Exmo. Sr. Dr. Joáo Pereira de Castro Pinto - Governador do Estado da Parahyba em 21/12/1922. 
condições para isso, permaneceu residindo no casebre e, como já havia sido informado de que era insalubre, passou a ser considerado um infrator. Portanto, não tinha mais para quem apelar. Em virtude de não ter cumprido a determinaçáo da Repartiçáo de Higiene para desocupar a moradia, ela teve que ser demolida. Essa realidade também foi vivenciada por Prudência Bezerra da Costa e pelo operário João Lourenço. Como suas casas eram de taipa e palha, foram condenadas pela Comissão de Higienização. Ambos alegaram que não podiam arcar com as despesas do aluguel de outros imóveis que não fossem os casebres onde residiam. Também não podiam construir uma casa conforme as recomendaçôes desse órgão. Seus casebres foram demolidos, os restos incendiados, e tais famílias passaram a habitar em casas de taipa nos arrabaldes da cidade ${ }^{7}$.

A imprensa paraibana tornou-se uma fecunda defensora da campanha de higienização do centro da cidade. $\mathrm{O}$ periódico católico A Imprensa publicava notas dos médicos sanitaristas, como a escrita pelo Dr. José Teixeira de Vasconcelos, lembrando ao prefeito que se mantivesse atento ao problema da insalubridade das ruas e das casas, principalmente porque tal condição era propícia à propagação das doenças:

O Senhor Diretor da Saúde Pública pede ao prefeito lançar as vistas para a casa $n^{\circ} 100$, à Rua Amaro Coutinho, pertencente ao Sr. Antônio dos Santos Nóbrega onde moraram durante longo tempo dois morféticos e que hoje está servindo para depósito de madeiras. Pede providências no sentido de ser destruída, pois se trata de uma fonte de perigo para a cidade. Também se incluem as Ruas da Raposa e do Melão ${ }^{8}$.

Conforme se depreende da nota, o Dr. José Teixeira de Vasconcelos, Diretor do Serviço de Saúde, esperava sensibilizar o

7 Ibidem.

8 A Imprensa, Parahyba, 14 jun. 1926, p. 06. 
prefeito acerca do risco para a cidade oferecido pela casa onde outrora habitaram os doentes, pois se tratava de um foco de contaminação, razão por que tinha que ser demolida. A perspectiva era de impedir que a varíola, doença que matara os dois homens, alastrasse-se pela cidade. Além da Rua Amaro Coutinho, o Dr. José Teixeira de Vasconcelos denunciou as Ruas da Raposa e a do Melão, visto não serem calçadas. De acordo com o médico, isso contribuía para que as chuvas abrissem cratera e acumulassem lixo e águas sujas vindas dos quintais das casas. A falta de calçamento nessas ruas estagnava as águas usadas, e, com o lixo, formavam-se focos de miasmas, que concorriam para aumentar o lamaçal, cujo odor só não era acentuado devido à ação salutar do tempo, com os efeitos benéficos e purificadores dos raios solares a renovarem constantemente $o$ ar. A permanência dessa situação levou o referido médico a recomendar ao prefeito da Capital da Parahyba algumas medidas básicas, por exemplo, a demolição das casas insalubres, a instalação da rede de esgoto nas Ruas da Raposa e do Melão, além da construção de um desinfetório pequeno e da aquisição de alguns fornos de incineração de lixo e de uma estufa móvel ${ }^{9}$. Portanto, formular propostas, encaminhá-las ao prefeito e coordenar as equipes de funcionários da Repartiçáo de Higiene que percorriam as ruas e as casas foram medidas que passaram a compor o cotidiano dos médicos sanitaristas vinculados a esse órgão. Mas, nem sempre, as soluçóes vieram a contento, exceto as demoliçóes praticadas pela Prefeitura.

Para os trabalhadores, a ação da Companhia de Higienizaçáo acarretou mudanças em seu cotidiano, visto que náo puderam continuar habitando as mesmas ruas que as elites habitavam. Por isso, os médicos recomendaram ao prefeito as Ruas da Raposa e do Melão como locais onde as classes trabalhadoras poderiam construir suas casas, desde que fossem de tijolos e cobertas de telhas, para obedecer ao Código de Postura. Embora houvesse a exigência quanto às condiçôes da casa, essas ruas não apresentavam nenhuma infraestrutura urbana, como calçamento, água encanada, iluminação elétrica e esgoto sanitário. Mesmo assim,

9 Relatório da Diretoria de Higiene do Estado da Parahyba - 1927. 
foram indicadas para os trabalhadores que chegavam à capital, porque, desde outrora, nelas moravam operários, estivadores, arrumadores e sapateiros, que exerciam suas funçóes nas áreas próximas ao Porto do Capim, na alfândega, em armazéns e na estaçáo ferroviária. Tratava-se de um contingente de trabalhadores necessários à produção e à reprodução de capital no espaço central urbano, mas seus espaços não foram preservados das determinaçóes estabelecidas. Os médicos consideravam que, alocados em certas ruas, tais profissionais evitariam a disseminação das doenças, e, caso surgisse uma epidemia, seria mais fácil aplicar as profilaxias. Todavia, os trabalhadores continuavam a trafegar por outras ruas da cidade, indiferentes à proibiçáo de construir suas casas nas áreas determinadas pelos médicos.

Apesar de os trabalhadores terem passado a morar nas áreas permitidas, não ficaram imunes aos olhos dos médicos. Constantemente, eram vigiados, para que seus costumes e hábitos não desestabilizassem a ordem pública nem esses espaços voltassem a dispor dos casebres de palha. A respeito disso, é pertinente a autorização do Prefeito Walfredo Guedes Pereira recebida pela viúva, Dona Francisca Maria da Conceição, para abrir uma bodega na Rua do Meláo, com a qual se manteria e aos seus filhos. A autorizaçáo fora concedida, desde que a casa a ser construída fosse de tijolo, coberta de telha e tivesse porta e janelas frontais.

A bodegueira, viúva e procedente do interior, chegou à capital em busca de meios para sobreviver, e por intermédio do semanário católico A Imprensa, endereçou carta ao Prefeito, pedindo-lhe um pedaço de chão onde pudesse construir uma casa, onde moraria e abriria uma bodega com seus parentes e amigos também vindos do interior do estado. Feita a concessão desse benefício, a pequena casa de porta, janela e váo único fora erguida com a ajuda dos familiares e dos vizinhos ${ }^{10}$.

De certa forma, a bodega da viúva Francisca Maria da Conceição quebrara os preceitos de higiene e salubridade determinados pelos médicos, pois, no espaço construído, ela passou a morar

A Uniáo, Parahyba, 18 mar. 1923, p. 3. 
com os quatro filhos e a negociar com frutas, verduras, porcos e galinhas criadas nos arredores da casa. Como estava na área da cidade determinada para alocar as classes pobres, o médico sanitarista não se incomodou com o fato de a viúva e seus filhos viverem em meio à insalubridade decorrente da criação de alguns animais domésticos.

Outro aspecto relevante é o de que os trabalhadores nem sempre cumpriram as determinaçóes de higiene impostas pelas elites. Para quem viera do mundo rural, onde era comum a criação de animais domésticos, o costume de criá-los não era visto como um risco à saúde, mas como uma atividade capaz de colaborar com a subsistência da família, o que é denotativo da coexistência de costumes rurais no meio urbano. Até 1929, o Código de Postura proibia a circulação de porcos, bodes, cabras e gados nas ruas da capital, uma evidência de que era comum a presença desses animais soltos nas ruas, decorrente de atividades rurais no espaço da cidade. Eis um dos motivos pelos quais, até essa data, o Jardim Público permanecera gradeado.

A condição e a estrutura das Ruas da Raposa e do Melão indicavam que, apesar do projeto de modernizar a cidade da $\mathrm{Pa}$ rahyba, ainda existiam, perto do centro, ruas onde porcos, cabras e vacas eram vistos em meio aos moradores e ameaçavam destruir os jardins e as praças.

O silêncio dos médicos em relação à bodega de $\mathrm{D}$. Francisca talvez se devesse ao fato de jamais os gêneros alimentícios negociados nesse local terem sido consumidos pelas elites. Logo, para os moradores do centro, não importava a qualidade do que lá fosse oferecido. Afora isso, a Rua da Raposa, mesmo no centro da cidade, ficava distante do perímetro beneficiado com os serviços e os equipamentos urbanos. Portanto, na compreensão dos citadinos, mesmo que essa artéria se mantivesse insalubre, jamais poderia contaminá-los, devido à distância que a separava da área saudável e higiênica da urbe onde residiam os ricos.

Apesar de se reconhecer o perigo representado pelas condiçóes de insalubridade em que viviam as classes trabalhadoras, pouco ou nada se fez para elaborar políticas públicas voltadas para a 
construção de casas populares. Em 1928, o parlamentar paraibano, Epitácio Pessoa, encaminhou ao Congresso Nacional uma mensagem em que sugeria aos deputados federais que discutissem sobre a questáo das casas populares no Brasil e a analisassem

do ponto de vista econômico e financeiro, pois a mesma exige abundantes modificaçóes na legislação existente, afim de que se apresse a solução das medidas que o caso exige e que se tornou mais premente, devido às demoliçôes de bairros inteiros que ocorreram nas diversas cidades do país, ultimamente remodeladas pelos serviços de saneamento e embelezamento. Atendendo a esse clamor, os dirigentes do Brasil devem se ocupar de providenciar com urgência para a realização desse imperioso melhoramento $\{. .$.$\} que$ vai trazer um abrigo melhor aos trabalhadores nacionais, a quem sempre faltaram às habitaçóes higiênicas e baratas ${ }^{11}$.

O pronunciamento do parlamentar paraibano em que chamava à atenção do Congresso Nacional para as condiçóes das classes pobres em meio à modernizaçáo das cidades, não surtiu efeito. É interessante observar que, nessa época (1928), seu sobrinho estava à frente do governo do estado da Parahyba. João Pessoa se empenhou no processo de modernizaçáo da capital e não realizou nenhuma ação em favor das classes pobres na perspectiva de beneficiá-las com os serviços de infraestrutura urbana implementados ${ }^{12}$.

Na Parahyba, a construção de casas populares na forma de vilas operárias, cujas casas eram salubres e obedeciam às regras de higienização determinadas pelos órgãos de saúde pública, não

11 “Habitaçōes populares”. A Imprensa, Parahyba, 17 dez. 1928.

12 Ibidem. 
foi uma realidade ${ }^{13}$. Não existiam vilas operárias na capital. A ausência dessa iniciativa fez com que as classes trabalhadoras, em geral, fossem responsáveis por construir suas próprias casas de palha e de taipa, nos arrabaldes de Cruz das Armas, Cruz do Peixe, Jaguaribe, Roger e Torre, enquanto os operários permaneceram nas ruas previamente definidas, ou seja, nas Ruas da Raposa e do Meláo, onde aqueles que, com os próprios custos, puderam erguer uma casinha de porta e janela, mas de tijolo e coberta de telha. Outro trecho do perímetro urbano que se destacou no cenário urbano como espaço destinado às classes trabalhadoras foi o final da Rua da República. A partir de 1922, ali se alocaram, principalmente, os trabalhadores especializados, como mecânicos, eletricistas, operadores de máquinas, condutores de bonde e maquinistas. Das imediaçóes da Central de Polícia até a Ponte do Baralho, as residências erguidas tinham o mesmo aspecto: casas geminadas simples, que compunham o mesmo padrão, contudo sem se tratar de uma vila operária. A paisagem do arruamento demonstra que a construção das casas obedeceu a determinada legislação: todas eram iguais e foram erguidas com recursos dos operários, supostamente os especializados, pois tinham condiçóes para isso.

Só em 1932, encontramos pequenas mobilizaçóes em prol da construçáo de casas para os trabalhadores. Foram iniciativas de religiosos católicos que recebiam subvençóes do Estado para tal fim, como, por exemplo, os irmáos Vicentinos, leigos ligados à Congregação de São Vicente de Paula ou a açôes filantrópicas em favor dos trabalhadores e dos pobres, com o intuito de retirá-los da rua e do convívio com os comunistas, sobretudo, dos aglomerados nas ruas da capital.

As vilas operárias apareceram apenas na cidade de Santa Rita,

13 A respeito da moradia das classes populares no Brasil, consultar: BLAY, Eva Alterman. Eu não tenho onde morar: vilas operárias em São Paulo. São Paulo: Nobel, 1985; ALVIM, Rosilene. A seduçáo da cidade: os operários camponeses e a fábrica dos Lundgren. Rio de Janeiro: Graphia, 1997; RAGO, Margareth. Do cabaré ao lar: a utopia da cidade disciplinar: Brasil 1890-1930. Rio de Janeiro: Paz e Terra, 1985; BONDUKI, Nabil. Origens da habitaçáo social no Brasil: arquitetura moderna, lei do inquilinato e difusão da casa própria. São Paulo: Estação Liberdade, 1998. 
como iniciativa dos empresários da fábrica de Tecido Tibiry, e na cidade de Rio Tinto, erguida em 1924, pertencente à Companhia Paulista de Tecido ${ }^{14}$. Na capital, as classes trabalhadoras, quando não ficaram à mercê da própria condição, foram socorridas pelos religiosos católicos. Mesmo assim, não ficaram livres dos olhares disciplinadores dos médicos sanitaristas.

Apesar de a falta de recursos públicos impedir açóes efetivas para a construção de casas populares e o recolhimento dos trabalhadores, o Estado não foi totalmente ausente nessa questão, porquanto subvencionou as instituiçóes de caridade que desenvolveram esse tipo de ação e contribuíam com a disciplinarização e a manutençáo da ordem.

\section{REFERÊNCIAS}

ALVIM, Rosilene. A seduçáo da cidade: os operários camponeses e a fábrica dos Lundgren. Rio de Janeiro: Graphia, 1997.

ARAÚJO, Edna Maria Nóbrega. Uma cidade, muitas tramas: a cidade da Parahyba e seus encontros com a modernidade (1880-1920). Recife: Dissertaçáo de Mestrado em História/Universidade Federal de Pernambuco, 2001.

BARRETO, Maria Cristina Rocha. Imagens da cidade: a ideia de progresso nas fotografias da Cidade da Parahyba (18701930). Joáo Pessoa: Dissertação de Mestrado em Ciências Sociais/Universidade Federal da Paraíba, 1996.

14 Acerca dessa questão, ver LOPES, José Sérgio Leite. A tecelagem dos conflitos de classe na cidade das chaminés. Brasília: EDUNB, 1998. Ao longo deste trabalho, o autor faz referência à cidade de Rio Tinto, no estado da Paraíba, sua relação com a fábrica, sobretudo, o crescimento da cidade a partir da vila operária, uma vez que, depois de demitidos os operários por não terem para onde ir, foram ocupando os arredores da vila e da fábrica. Ver também: DINIZ, Ariosvaldo da Silva. A maldição do trabalho: homens pobres, mendigos e ladrôes no imaginário das elites nordestinas - 1850-1930. João Pessoa: UFPB, 1988; MACEDO, Maria Bernadete Ferreira de. Inovaçóes tecnológicas e vivência operária: o caso de Rio Tinto (1950-1970). João Pessoa: Dissertação de Mestrado em Economia/Universidade Federal da Paraíba, 1988. 
BERMAN, Marshall. Tudo que é sólido desmancha no ar: a arquitetura da modernidade (Tradução de Carlos Felipe Moisés e Ana Maria L Ioriatti.). São Paulo: Companhia das Leras, 1986.

BLAY, Eva Alterman. Eu náo tenho onde morar: vilas operárias em São Paulo. Sáo Paulo: Nobel, 1985.

BÓGUS, Lúcia Maria M.; WANDERLEY, Luiz Eduardo W. A luta pela cidade em Sáo Paulo. Rio de Janeiro: Cortez, 1992.

BONDUKI, Nabil. Origens da habitaçáo social no Brasil: arquitetura moderna, lei do inquilinato e difusão da casa própria. Sáo Paulo: Estaçáo Liberdade, 1998.

DINIZ, Ariosvaldo da Silva. A maldiçáo do trabalho: homens pobres, mendigos e ladróes no imaginário das elites nordestinas - 1850-1930. João Pessoa: UFPB, 1988.

FARIAS, Ana Maria S. M. Urbanizaçáo e modernidade: a construçáo do espaço urbano de João Pessoa (dos anos 20 aos anos 70). Recife: Tese de Doutorado em História/Universidade Federal de Pernambuco, 1997.

LOPES, José Sérgio Leite. A tecelagem dos conflitos de classe na cidade das chaminés. Brasília: Editora da UnB, 1998.

MACEDO, Maria Bernadete Ferreira de. Inovaçóes tecnológicas e vivência operária: o caso de Rio Tinto (1950-1970). João Pessoa: Dissertação de Mestrado em Economia/Universidade Federal da Paraíba, 1988.

RAGO, Margareth. Do cabaré ao lar: a utopia da cidade disciplinar (Brasil 1890-1930). Rio de Janeiro: Paz e Terra, 1985. 


\section{JORNAIS, ATAS E RELATÓRIOS}

Atas das reunióes da Associaçáo Médica da Parahyba de 1923 a 1930.

A Imprensa, Parahyba, 14 jun. 1926; 17 dez. 1928.

A União, Parahyba, 1º mar. 1913; 18 mar. 1923; 25 jan. 1920.

Relatório da Chefatura de Polícia encaminhado ao Exmo. Sr. Dr. Joáo Pereira de Castro Pinto - Governador do Estado da Parahyba em 21/12/1922.

Relatório da Diretoria de Higiene do Estado da Parahyba $-1927$. 